on the shaft support and reinforcement at depths greater than $700 \mathrm{zm}$.

References

1. Pleshko M. S., Stradanchenko S. G., Maslennikov S. A., Pashkov $O$. V. Study of technical solutions to strengthen the lining of the barrel in the zone of influence of construction near-wellbore production. ARPN Journal of Engineering and Applied Sciences. 2015. Vol. 10(1). pp. 14-19.

2. Walton G., Kim E., Sinha S., Sturgis G., Berberick D. Investigation of shaft stability and anisotropic deformation in a deep shaft in Idaho, United States. International Journal of Rock Mechanics and Mining Sciences. 2018. Vol. 105. pp. 160-171.

3. Kaledin O. S. Innovative technologies for the construction of superdeep mine shafts. Mining Journal. 2014. No. 4. pp. 77-81.

4. Tarasov V. V., Koshev G. Ya., Zagvozdkin I. V. Solution of security problems in the construction of vertical shafts at potash deposits. Industry labour safety. 2015. Vol. 8. pp. 64-67.

5. Tarasov V. V., Pestrikova V. S. Overview of emergencies that occurred at the Verkhnekamsk potassium salt deposit during the mining of shafts. GIAB. 2015. No. 5. pp. 23-29.

6. Xiaowei Feng, Nong Zhang, Fei Xue, Zhengzheng Xie. Practices, experience, and lessons learned based on field observations of support failures in some Chinese coal mines. International Journal of Rock Mechanics and Mining Sciences. 2019. Vol. 123. 104097. DOI: 10.1016/j.jirmms.2019.104097

7. Corkum A. G., Damjanac B., Lam T. Variation of horizontal in situ stress with depth for long-term performance evaluation of the Deep Geological Repository project access shaft. Interna- tional Journal of Rock Mechanics and Mining Sciences. 2018. Vol. 107. pp. 75-85.

8. Strickland B., Board M., Sturgis G., Berberick D. Elliptical shaft excavation in response to depth induced ground pressure. SME Annual Conference and Expo: The Future for Mining in a Data-Driven World. 2016. pp. 407-412.

9. Kharisov T. F. Mine shaft rock walls convergence investigations in the conditions of the out-of-limit state of the borehole massif. Izvestiya vuzov. Gornyi zhurnal. 2017. No. 5, pp. 46-51.

10. Sousa L. R., Sousa R. L., Vargas Jr. E., Velloso R., Karam K. Risk assessment on $\mathrm{CO}_{2}$ injection processes and storage. Rock Mechanics and Rock Engineering. 2017. Vol. 3(12). pp. 359-397.

11. Pleshko M. S., Silchenko Yu. A., Pankratenko A. N., Nasonov A. A Improvement of the analysis and calculation methods of mine shaft design. GIAB. 2019. No. 12. pp. 55-66.

12. Pleshko M. S., Pashkova O. V., Nasonov A. A. Analysis of geometrical nonuniformityf lining in operating shafts and its influence on shaft stability. Gornyi Zhirnal. 2015. No. 3. pp. 33-37. DOI: $10.17580 /$ gzh.2015.03.05

13. He M., Li. C., Gong W., Sousa L. R., Li S. Dynamic tests for a constant-resistance-large-deformation bolt using a modified SHTB system. Journal of Tunneling and Underground Space Technology. 2017. Vol. 64. pp. 103-116.

14. Shuxue D., Hongwen J., Kunfu C., Guo'an X. Bo, M. Stress evolution and support mechanism of a bolt anchored in a rock mass with a weak interlayer. International Journal of Mining Science and Technology. 2017. Vol. 27. pp. 573-580.

\title{
GEOMECHANICAL SUBSTANTIATION OF THE NORTHEASTERN PIT WALL STABILITY IN KURZHUNKUL MINE
}

\section{Introduction}

Structural heterogeneity, extensional tectonics, jointing and broken bedding are the critical factors of higher concern in mineral mining safety. All other geological and geophysical processes are controllable and are governed by the extensional tectonics $[1,2]$.

From the engineering geology data, the Kurzhunkul open pit mine field is intersected by premineral NE-striking faults with NW dips at $80-85^{\circ}$ and by NW-striking faults with SW dips at the same angles, and represents a small- and medium-size blocky rock mass. Tectonic faults are oriented ether north-southward, or west-eastward, north-eastward and north-westward, and represent either normal faults, or shifty faults and overthrusts, which condition the broken blocky structure of the region.
Kurzhunkul magnetite deposit is located in the Kostanai Region of Kazakhstan and is an open pit mining project of Sokolovsko-Sarbay Mining and Production Association (SSGPO) since 1983. The current depth of the open pit is $240 \mathrm{~m}$ (Level-28m). It is expected that Kurzhunkul pit reaches the depth of $290 \mathrm{~m}$. The deformation determinant in Kurzhunkul mine is its geological structure represented by complex faulting. Special care and attention should be paid to the northeastern pit wall which is a zone of large and closely spaced tectonic faults essentially extended along the strike and dip of the deposit, and depthward the pit. Unfavorable bedding conditions in combination with weak physical and mechanical properties of fracture fillers can induce movement of rock blocks during extraction of mineral reserves from the weak zone of the northeastern pit wall. This study offers the geomechanical substantiation of stability of NE Kurzhunkul pit wall which is most heavily intersected by tectonic faults and has low strength characteristics.

Keywords: open pit mine, tectonic faults, stability, physical and mechanical properties, stability factor.

DOI: $10.17580 / \mathrm{em} .2021 .01 .06$ 
The premineral NE-striking faulting is synvolcanic normal faults in docite and quartz porphyry, with zones of fragmented and heavily jointed rocks in contact zones. These faults feature disintegration together with consolidation of rocks mass with joints healed by strong minerals. The NWstriking faulting regenerated after orogenesis represents fragmentation zones and sandy-clayey residuum; it considerably complicates the rock mass structure and promotes its disintegration.

\section{Research results}

Based on the lab-scale strength tests, Kurzhunkul rocks are assumed as medium strong to very strong. Depthward the rock mass, the strength of rocks varies from $39.0 \mathrm{MPa}$ to $89.1 \mathrm{MPa}$. The footwall (eastern pit wall) is heavier faulted as against the hanging wall. Strong jointing and low strength of rocks in the footwall are connected with the local tectonic faults. For example, metasomatic rocks in the southeast of the open pit have half as high strength as in the southwest.

The main part in formation of unstable blocks in enclosing rocks of Kurzhunkul open pit is taken by the combination of differently oriented faults. Figure 1 offers 3D visualization of the positions of main NW-striking faults 1 to 6 as well as NE-striking faults (in the horizontal plane) relative to each other and to Kurzhunkul pit walls from the mapped boring data.

The faulting governs the block hierarchical structure of Kurzhunkul rock mass. The faults split the rock mass into blocks from ten to hundred meters in size [3-6].

Tectonic stresses and blasting can induce displacements of structural blocks along fractures both in the line of the pit wall and towards the pit. The highest danger is constituted by faults in the northern pit wall as they dip towards the minedout void, and in case of instability, the structural blocks will move along weak surfaces to the pit (Figs. 1 and 2).

The northeastern pit wall is cut with a series of faults 1-6 with the northwestward strike at azimuth of $295-320^{\circ}$ and with the southwestward dip (to the pit) at angles of $80-85^{\circ}$. These faults are long and are traceable to the full length. A large anticlinal fold is well detected in the longitudinal faults here. The surfaces of lithogenetic vertical joints have a dip towards the work face. Weakening of the rock mass will take place in the line of the faults. In the zones of large faults, Paleozoic rocks of Kurzhunkul open pit are weathered, heavily jointed and fractured. The strength of the rock mass in shearing in parallel to the faults is governed by the shear strength of the faults. This area is susceptible to deformation in the form of subsidence, rockslide and rock falls along tectonic fractures.

Considering occurrence of layers at the angles $15-25^{\circ}$ towards the pit, the rock mass structure will also be the decisive factor in estimating possible failure mechanisms. The prevailing system of flat-lying joints (system 1 ) in adjacent rock mass of Kurzhunkul pit will cause rockslides in the areas of developed flat-dipping bedding, while steep joints (system 2) can induce failure of benches during undercutting of rock blocks lying on the weak surface. The triggers will be seismic effects produced by blasts, water intrusions and loads generated by mining machinery.

Generally, the northern and northeastern pit walls are most susceptible to deformation and represent a weak zone. The weak zone in NE pit wall, alongside with the unfavorably
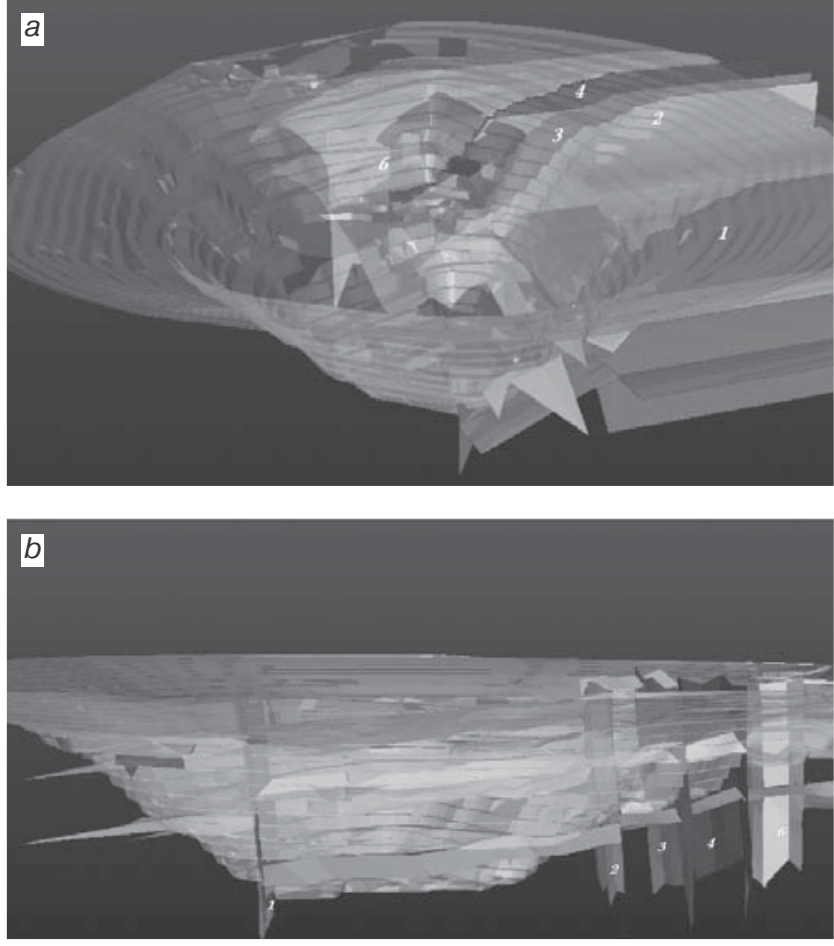

Fig. 1. Main faults intersecting ultimate pit limits in Kurzhunkul mine:

(a) view from the south; (b) view from the east

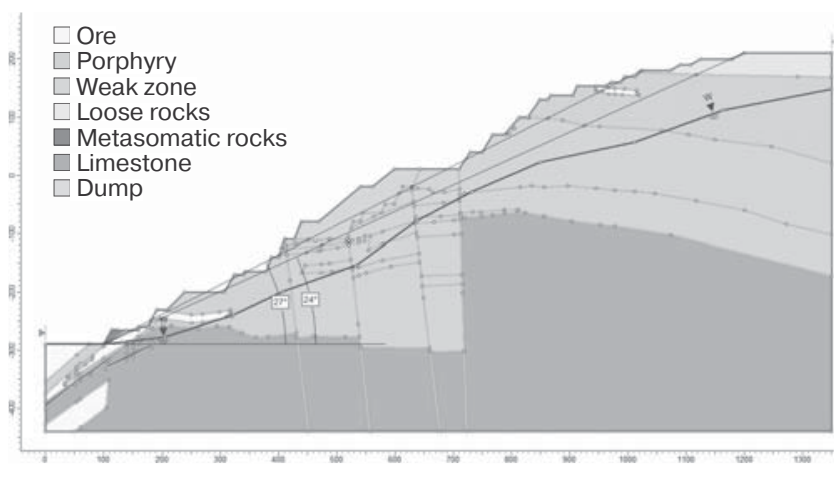

Fig. 2. Elevation view along profile 6 (weak zone in NE pit wall)

oriented faults, have low strength characteristics of weak surfaces. This fact is proved by the data obtained in borehole $11 \mathrm{i}$ drilled in this pit wall: rock mass to Level $+105 \mathrm{~m}$ is composed of heavily jointed porphyry of medium strength (39 MPa on the average), core is $75 \%$ crushed rocks, the average size of particles is $2-7 \mathrm{~cm}$. The joints will have the highest impact on NE pit wall stability.

Mining safety can be ensured owing to comprehensive analysis of geological structure and geotechnical features of the deposit. The determinant of the pit wall stability is the structural geology as differently oriented tensile fractures form potential sliding triangles in the pit walls. Potentially unstable walls and benches are detected by analyzing parameters of structural faults identified in the pit wall rock mass [7-9].

The stress-strain behavior of enclosing rock mass surrounding the pit in the current conditions is characterized by 
low stresses according to the data of borehole slotting and numerical modeling.

Stability estimation of NE Kurzhunkul pit wall is carried out with Rocscience Slide using the methods of limiting equilibrium by comparing the external (shearing) and internal (retaining) forces in line with the procedure developed by VNIMI [10].

For the stability calculation of the weak zone in NE pit wall, profile 6 was plotted by the data from certified boreholes (see Fig. 2). The slope of the pit wall is $27^{\circ}$ in strong rocks and is $24^{\circ}$ at the ultimate pit limit. The location and orientation of the profile are chosen from the criterion of the highest hazard (pit wall failure).

The initial strength characteristics of pit wall rock mass are added with the stability factor $n=1.3$ [11]. The slope stability calculations for Kurzhunkul open pit mine included such determinants of stability as:

- physical and mechanical properties of rocks and weak surfaces (Tables 1-3);

- water content including groundwater

- impact induced by mining operations (7 points as per survey results).

The source data for the strength calculation of weak NE pit wall rock mass (area of tectonic faults and weak contacts) (Table 3) were assumed to be the most probable values of strength of a crack filler from the core tests [12-15].

The stability calculations for the design pit boundary along profile 6 (weak zone in NE pit wall) included some variants, namely (Table 4):

- design pit boundary without a dump and without regard to impact from blasting;
Table 1. Estimated strength characteristics of loose rocks in the northeastern pit wall of Kurzhunkul mine (EEG - element of engineering geology)

\begin{tabular}{|c|c|c|c|c|c|c|}
\hline \multirow{2}{*}{ EEG no. } & \multirow{2}{*}{ EEG } & \multirow{2}{*}{$\begin{array}{c}\text { Density } \\
\mathrm{\gamma}, \mathrm{kg} / \mathrm{m}^{3} \cdot 10^{3}\end{array}$} & \multirow{2}{*}{$\begin{array}{c}\text { Cohesion } \\
C, \mathrm{MPa}\end{array}$} & \multirow{2}{*}{$\begin{array}{l}\text { Internal friction } \\
\text { angle } \varphi \text {, deg }\end{array}$} & \multicolumn{2}{|c|}{ Estimated data } \\
\hline & & & & & $C, \mathrm{t} / \mathrm{m}^{2}$ & $\varphi$ \\
\hline 1 & Loam edQIV & 2.01 & 0.03 & 15 & 2.35 & 11.6 \\
\hline 5 & Clay $P_{2 c a}$ & 1.67 & 0,08 & 11.5 & 6.27 & 8.9 \\
\hline 6 & $\begin{array}{l}\text { Sandstone-banded } \\
\text { clay } \mathrm{P}_{2 \mathrm{ts}}\end{array}$ & 1.56 & 0.13 & 21.0 & 10.2 & 16.4 \\
\hline
\end{tabular}

Table 2. Estimated strength characteristics of strong rocks in the northeastern pit wall of Kurzhunkul mine (EEG - element of engineering geology)

\begin{tabular}{|c|c|c|c|c|c|c|c|c|}
\hline \multirow[b]{2}{*}{$\begin{array}{c}\text { EEG } \\
\text { no. }\end{array}$} & \multirow[b]{2}{*}{ Rock } & \multirow[b]{2}{*}{$\begin{array}{l}\text { Density g, } \\
\mathrm{kg} / \mathrm{m}^{3} \cdot 10^{3}\end{array}$} & \multicolumn{2}{|c|}{ Core test data } & \multirow[b]{2}{*}{$\begin{array}{c}\text { Structural } \\
\text { weakening } \\
\text { coefficient } \\
\lambda\end{array}$} & \multicolumn{3}{|c|}{ Estimated data } \\
\hline & & & $\begin{array}{c}\text { Cohesion } \\
\mathrm{C}_{\mathrm{o}}, \mathrm{MPa}\end{array}$ & $\begin{array}{c}\text { Internal } \\
\text { friction } \\
\text { angle } \\
\varphi \text {, deg }\end{array}$ & & $\begin{array}{l}\text { Cohesion } \\
\mathrm{C}_{\mathrm{m}}, \mathrm{MPa}\end{array}$ & $\begin{array}{c}\text { Cohesion } \\
C_{m}, t / m^{2}\end{array}$ & $\begin{array}{l}\text { Internal } \\
\text { friction } \\
\text { angle } \varphi\end{array}$ \\
\hline 9 & Porphyry & 2.61 & 11.33 & 31.67 & 0.0474 & 0.41 & $41.6 / 36$ & 25.4 \\
\hline 10 & $\begin{array}{c}\text { Metasomatic } \\
\text { rocks }\end{array}$ & 2.73 & 16.74 & 34.24 & 0.0352 & 0.45 & 46.23 & 27.6 \\
\hline
\end{tabular}

\section{Table 3. Strength characteristics of weak surfaces and contacts}

\begin{tabular}{|c|c|c|c|c|c|c|c|}
\hline \multirow[b]{2}{*}{ no. } & \multirow[b]{2}{*}{ Weak surfaces } & \multicolumn{2}{|c|}{ Core test data } & \multirow{2}{*}{$\begin{array}{c}\text { Structural } \\
\text { weakening } \\
\text { coefficient } \lambda\end{array}$} & \multicolumn{2}{|c|}{ Estimated data } & \multirow[b]{2}{*}{$\begin{array}{l}\text { Density } \gamma \\
\mathrm{kg} / \mathrm{m}^{3} \cdot 10^{3}\end{array}$} \\
\hline & & $\begin{array}{c}\text { Cohesion } \\
\mathrm{C}_{0}, \mathrm{MPa}\end{array}$ & $\begin{array}{c}\text { Cohesion } \\
\mathrm{C}_{0}, \mathrm{MPa}\end{array}$ & & $C^{\prime}, t / m^{2}$ & $\varphi^{\prime}$, deg & \\
\hline 1 & Internal dump & & & & 0 & 34 & 2.07 \\
\hline 2 & Weak zone in NE pit wall & 8.9 & 29 & 0.02 & 13.3 & 23 & 2.67 \\
\hline
\end{tabular}

- design pit boundary with a dump and without regard to impact from blasting;

- design pit boundary with a dump and with regard to impact from blasting (minimal seismicity coefficient $\mu=0.25$ as per Construction Regulations SP RK 2.03-30-2017) (Fig. 3).

\section{Conclusions}

The calculations show that additional load exerted on the weak zone of NE pit wall by the internal dump improves the pit wall stability. The weak zone of NE pit wall at its ultimate limit in the calculation variant without regard to impact from blasting has the minimal stability factor $\mathrm{SF}=(1.00 \div 1.10)$ and, thus, the pit wall is unstable (See Table 4). The broken bedding

Table 4. Stability calculations for weak NE pit wall in case of increasing depth of Kurzhunkul mine to (-290) $\mathrm{m}$

\begin{tabular}{|c|c|c|c|c|c|c|c|}
\hline $\begin{array}{c}\text { Profile } \\
\text { no. }\end{array}$ & Pit wall & Calculation variant & $\begin{array}{c}\text { Boundaries of minimal } \\
\text { triangle of failure, } \mathrm{m}\end{array}$ & $\begin{array}{c}\text { Pit wall } \\
\text { height, } \mathrm{m}\end{array}$ & $\begin{array}{c}\text { Pit wall } \\
\text { slope, deg }\end{array}$ & Min SF & Pit wall condition \\
\hline \multirow{2}{*}{6} & $\begin{array}{c}\text { Design boundary with regard } \\
\text { to ground water (no dump, } \\
\text { blasting effect excluded) }\end{array}$ & $(-110) \div(160)$ & 370 & 30 & 1.008 & nearly limiting \\
\cline { 3 - 8 } & Weak zone \\
in NE pit wall & $\begin{array}{c}\text { Design boundary with regard } \\
\text { to ground water (dump, } \\
\text { blasting effect excluded) }\end{array}$ & $(-200) \div(160)$ & 360 & 28 & 1.10 & stable \\
\cline { 3 - 8 } & $\begin{array}{c}\text { Design boundary with regard } \\
\text { to ground water (dump, } \\
\text { blasting effect included) }\end{array}$ & $(-200) \div(160)$ & 360 & 28 & 0.892 & unstable \\
\hline
\end{tabular}




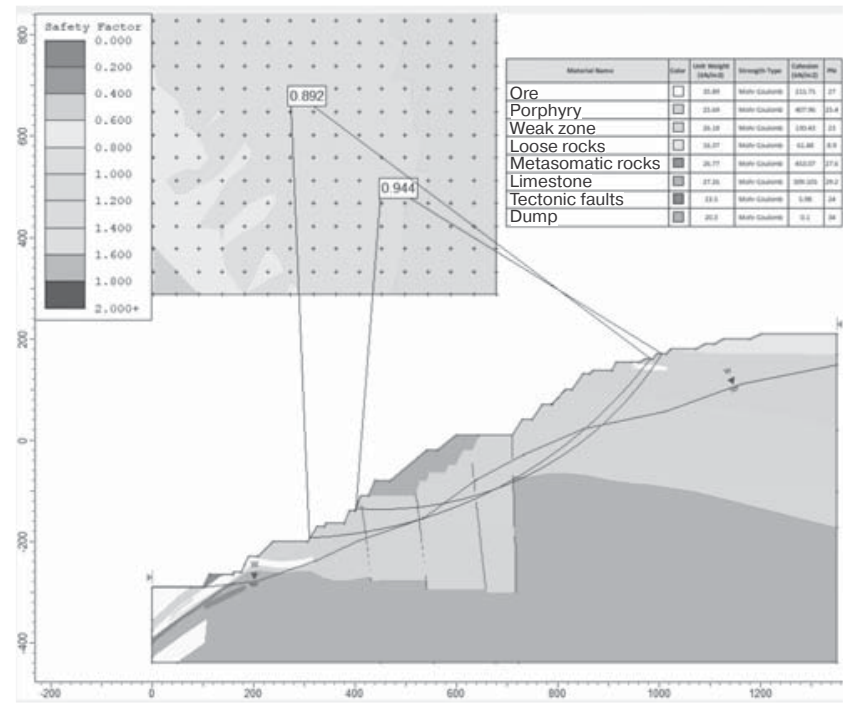

Fig. 3. Stability calculation results for weak zone in NE pit wall at design limits (with regard to influence of groundwater, blasting and internal dump)

conditions in combination with weak physical and mechanical properties of crack fillers will promote displacement of rock mass during mining of middle levels of NE pit wall. The anthropogenic effect and watering of rock mass will contribute to deformation of the pit wall areas adjacent to the zones of fractures and faults. This fact is proved by the stability calculations (See Table 4).

For the stability maintenance in the northeastern area of the pit, the operating sites on Levels $(-110)-(+10) \mathrm{m}$ at the ultimate pit limits are additionally loaded by an internal dump. The internal dump will act as a counterforce to prevent development of shearing along the faults in the northern and northeastern pit walls. The extension of the counterforce is governed by the girtwise length of the weak zone in the pit wall rock mass.

On the whole, the northeastern area of the pit requires monitoring of deformation, applying of low-impact technology of blasting at the ultimate pit limit, efficient drainage of the pit wall rock mass as disintegrated rocks within the weak zone will favor enhanced permeability of water, and special slope reinforcement measures. Within the boundaries of the faulted zones in NE pit wall, it is prohibited to undercut layers with continuous fractures and faults oriented towards the mined-out void.

The research results and recommendations made can ensure safety of mining at the ultimate pit limit with beneficial effect on mining performance. The slope stability of pit wall and benches provides reduction in the volume of striping at the sustained stability of the pit wall at the maximal allowable slope. The geomechanical research data and calculations make it possible to eliminate possible losses due to landsliding, violation of mining schedule, damage of transportation roads, loss of useful minerals and downtime of mining machines.

\section{Acknowledgement}

The study was carried out with grant financing in framework of Project No. AR08053358 Rock Mass Control Based on the Integrated Geomechanical Model toward Mining Safety.
References

1. Zhirov D. V., Klimov S. A., Melikhova G. S. Structural engineering zoning of Kovdor baddeleyite-apatite-magnetite and weakly ferrous apatite deposit as the framework for the steep pit wall design. Ecology Strategy for the Mining Industry Advancement - Shaping a New Vision in Natural Resources Management. Conference Proceedings. Apatity: KSC RAS, 2014. DOI: $10.13140 / 2.1 .4208 .2885$

2. Zhirov D. V., Melikhova G. S., Reshetnyak S. P., Rybin V. V., Melikhov M. V. Engineering-geological substantiation of solutions on streng-thening and stabilizing hard rock mass in open-pits. GIAB. 2015. No. 556. pp. 164-174.

3. Kazikaev D. M., Kozyrev A. A., Kasparyan E. V., lofis M. A. Management of geomechanical processes in the development of mineral deposits. Moscow: Publishing house mining book, 2016. 490 p.

4. Kasparyan E. V., Fedotova Yu. V. Stress-strain state in rock mass of the Khibiny deposits and tasks of geomechanical zoning. GIAB. 2015. No. 5. pp. 97-107.

5. Balek A. Ye. Taking into account the mosaic structure of stress-strain state of rock mass during solving the practical tasks of mining. Problems of subsoil use. 2018. No. 3. pp. $140-150$.

6. Sashurin A. B., Balek A. E., Panzhin A. A., Usanov S. V. Innovative technology for diagnosis of geodynamic activity in geological media and safety assessment of subsoil use objects. Gornyi Zhurnal. 2017. No. 12. pp. 16-20. DOI: 10.17580/ gzh.2017.12.03

7. Berdinova N. O., Sedina S. A., Shamganova L. S., Kalyuzhny E. S. Prediction of strains in strong rock mass of the Kurzhunkul open pit mine by the kinematic analysis. GIAB. 2020. No. 4. pp. 58-68.

8. John R., Peter S. Guidelines for open pit slope design. Australia: CSIRO Publishing, 2009.

9. Obregon C., Mitri H. Probabilistic approach for open pit bench slope stability analysis - A mine case study. International Journal of Mining Science and Technology. 2019. Vol. 29, No. 4. pp. 629-640.

10. Kozlov Yu. S., Mochalov A. M., Pushkarev V. I., Sapozhnikov V. T., Fisenko G. L. Guides for slope design of pit walls, benches and dumps in open pit mines under construction. Leningrad : VNIMI, 1972. $162 \mathrm{p}$.

11. Rybin V. V., Konstantinov K. N., Kalyuzhny A. S. Integrated approach to slope stability estimation in deep open pit mines. Eurasian mining. 2019. No. 2. pp. 23-26. DOI: 10.17580/ em.2019.02.05

12. GOST 21153.8-88. Rocks. Method for determination of triaxial compressive strength. 01.07.1989. Moscow : Izdatelstvo standartov, 1988.

13. Eremin G. M. Improvement of methods to determine strength characteristics and deformability of rocks mass in new technologies of open pit mining and underground excavation stability. Moscow : Gornaya Kniga, 2016. 36 p.

14. Ilnitskaya E. I., Teder R. I., Vatolin E. S., Kuntysh M. F. Rock Properties and Methods of their Determination. Moscow: Nedra, 1969. 392 p.

15. Rakishev B. R., Kuzmenko S. V., Sedina S. A., Tulebayev K. K. The analysis of influence of mining-geological factors on edges stability on the example of the Sarbai pit. Reports of the national academy of sciences of the Republic of Kazakhstan. 2018. Vol. 3, No. 319. pp. 133-140. 